Article

\title{
Ethylene Methacrylic Acid (EMAA) Single Splat Morphology
}

\section{Wei Xie ${ }^{1}$, James Wang ${ }^{1}$ and Christopher C. Berndt ${ }^{1,2, *}$}

1 IRIS, Faculty of Engineering and Industrial Sciences, Swinburne University of Technology, PO Box 218, Hawthorn, VIC 3122, Australia; E-Mails: xie_samuel@yahoo.com.au (W.X.); jawang@swin.edu.au (J.W.)

2 Department of Materials Science and Engineering, Stony Brook University, Stony Brook, NY 11794, USA

* Author to whom correspondence should be addressed; E-Mail: cberndt@swin.edu.au; Tel.: +61-0-3-9214-8706; Fax: +61-0-3-9214-5050.

Received: 9 April 2013; in revised form: 3 June 2013 / Accepted: 4 June 2013 / Published: 14 June 2013

\begin{abstract}
A single splat is the building block of a thermal spray coating; thus, investigating single splats is essential to understanding thermal spray coatings and their properties. In this study, the morphology of flame sprayed ethylene methacrylic acid (EMAA) splats, deposited at various stand-off distances (SODs) onto glass and mild steel substrates were investigated using a scanning electron microscope, Leica $M$ Stereo-microscope, the WYKO surface profiler and the ContourGT surface profiler. This work analyzed the effect of the process variables on EMAA splat morphology. The modeling of the temperature versus velocity (TV) map, the temperature versus stand-off distance (TS) map and the velocity versus stand-off distance (VS) map of EMAA single splat were presented.
\end{abstract}

Keywords: EMAA; splats; wettability; roughness; morphology; thermal spray

\section{Introduction}

Many parameters influence the structure of a single splat, and also, therefore, the thermal spray coating and its properties. The parameters are particle velocity; temperature; molten state; oxidation state; the substrate tilting angle; surface roughness; oxide layer composition and its thickness; and desorption of adsorbents and condensates. The physical properties of thermal conductivity and the 
wettability at impact between the thermal sprayed particle and the substrate influence the individual splat geometry [1,2] and the coating build-up and, consequently, the coating properties. The coating formation process is generally determined by the prime processing variables, which include substrate roughness, substrate temperature, impact velocity, stand-off distance (SOD), and the nature of the local atmospheric environment [3-6]. Many of these factors are inter-related. For example, SOD will influence the impact velocity as well as the substrate temperature due to heat transfer from the thermal spray torch.

The surface condition [7-10] and the wettability of the substrate play an important role in the morphology of splats [11]. There are three factors affecting the wettability of the substrate. The first factor includes the substrate roughness, porosity and also the physical properties, such as thermal conductivity. Higher surface roughness enhances wettability of the substrate [12], and higher thermal conductivity of the substrate, gives rise to poor wettability of the substrate [13]. The second factor includes the composition, thickness and morphology of the oxide layer on the surface of the substrate; these are affected by the preheating rate, temperature and time. The thickness of the oxide layer affects the roughness of the substrate [14], and thus modifies the wettability of the substrate [1]. The third factor concerns condensates or adsorbents on the substrate surface. A higher content of condensates or adsorbates on the surface of the substrates, lower the wettability of the substrate; thus, more splash splats occur $[8,9,15]$.

Substrate wettability is one factor that influences the maximum diameter of a single splat. Other factors include the droplet initial diameter, impact velocity, surface tension and viscosity. The wettability of the substrate plays a significant role when the impact velocity becomes low. The higher the wettability of the substrate, then the larger the diameter of a single splat [16], and the less likelihood of a splash splat [17] feature.

The morphology of a single splat is related to the critical preheating temperature, $T_{c}$, of the substrate [18]. This temperature is also defined as the transition temperature $\left(T_{\mathfrak{t}}\right)$ of the substrate by Fukumoto [19]. The splats are more disc-like when the substrate temperature is over $T_{c}$. The splats are extensively fingered when the temperature is below $T_{c}$. The value of $T_{c}$ is quite sensitive to the splat material rather than to the substrate [18]. For alumina and zirconia, $T_{c}$ is around 200 to $250{ }^{\circ} \mathrm{C}$ [20,21] for disc splats deposited on low-carbon steel, stainless steel, aluminum alloys, zirconia, and alumina substrates. For EMAA, $T_{c}$ is around $90-100{ }^{\circ} \mathrm{C}$ [22] for deposition onto mild steel.

Many spray process parameters correlate to each other. The splat spread factor decreases with an increase in substrate roughness [23]. When the spray angle increases, splats exhibit an elliptical shape, and the aspect ratio; i.e., the ratio of the length of the major axis to that of the minor axis of the splats, increases accordingly. The splats become fingered for spray angles less than $30^{\circ}$ [18]. Spray process variables influence the physical nature of the intrinsic building blocks of thermal spray coatings; i.e., the splat morphology $[1,24]$.

The current work aims to investigate the effects of stand-off distance and the surface condition on the splat morphology. The modeling of the temperature versus velocity (TV) map, the temperature versus stand-off distance (TS) map and the velocity versus stand-off distance (VS) map of EMAA single splat were presented. In this paper, a splat refers to a pan cake shaped deposit, while a splash exhibits irregular and non-circular geometry with fingers and other features that may be connected or within the vicinity of a central mass of the coating material. An unmelted splat refers to particles that 
are partially melted and retain the near-spherical morphology of the feedstock material; whereas 're-solidified splat' represents melted particles that have re-solidified and also maintain the near-spherical morphology of the feedstock material. Unmelted splats and re-solidified splats reflect a low processing temperature brought about by either short or long SODs, respectively.

\section{Experimental Procedure}

The flame spray (FS) process was performed with a Powder Pistol 124 PFS (Thermoplastic Powder Coatings, Big Spring, TX-USA) that is typical of an industrial setting. The combustion gas was a propane/air mixture in the ratio of 1:2 at a flow rate of $40 \mathrm{~L} / \mathrm{min}$ with the propane adjusted to $0.1 \mathrm{MPa}$.

A Tecflo 5102 powder feeder was used to spray single splats. The direction of droplet deposition was perpendicular to the substrate surface. A much reduced feedstock delivery rate was necessary; only one traverse with a traverse speed of $25 \mathrm{~cm} / \mathrm{sec}$ across the substrate was performed to achieve single splats that did not overlap. It can be argued that these process conditions do not accurately represent industrial settings since typical industrial spray parameters would rule out the creation of non-overlapping splats. However, it is necessary to point out that intent of the present study is to form single, individual splats for scientific observations.

The EMAA, purchased from Innotek Powder Coatings LLC (TX-USA), exhibited a particle size range from $30 \mu \mathrm{m}$ to $400 \mu \mathrm{m}$ and an angular morphology, as expected from the cryogenic grinding process used to manufacture the powders [25].

The mild steel (grade 250) was purchased from Melsteel Pty. Ltd. from Australia. The composition of the mild steel substrates was $0.42-0.48$ at $\%$ for $\mathrm{C}, 0.05-0.35$ at $\%$ for $\mathrm{Si}, 0.6 \%-0.9$ at $\%$ for $\mathrm{Mn}$ and less than 0.06 at $\%$ for both $\mathrm{S}$ and $\mathrm{P}$. The mild steel substrates of $20 \mathrm{~mm} \times 30 \mathrm{~mm}$ area and $2 \mathrm{~mm}$ thick for single splat studies were polished using silicon carbide sandpaper and diamond compound to achieve a $0.2 \mu \mathrm{m}$ finish (Ra); whereas the glass slides were used in the as-received condition and were of average roughness $(\mathrm{Ra}) 0.02 \mu \mathrm{m}$.

The samples were cleaned by sequential sonication for five minutes respectively in each of the following: dichloromethane, acetone, hexane, acetone and methanol; followed by rinsing with MilliQ water (MilliQ A10, Millipore, Switzerland). The mild steel substrates were heated by the flame until the substrate temperature reached to $100{ }^{\circ} \mathrm{C}$.

The splat profiles, diameter, thicknesses and volume were analyzed with a WYKO NT1100 non-contact optical surface profilometer (VECCO, NY, USA), ContourGT (Bruker AXS Inc., WI, USA) and accompanying software Vision 4.2 (Veeco Instruments Inc., NY-USA).

The roughness was measured using an AlphaStep ${ }^{\circledR}$ D-120 Stylus Profiler (KLA-Tencor, CA-USA), a WYKO NT1100 non-contact optical surface profilometer.

The deposit morphology was examined using both Leica M Stereo-microscope (Leica Microsystems, Wetzlar-Germany) and a scanning electron microscopy (ZEISS SUPRA 40VP FESEM, Carl Zeiss Microscopy, LLC, Oberkochen, Germany). Samples were gold coated within a DYNAVAC CS 300 deposition system prior to the SEM analysis. In excess of 400 splats were examined for each thermal spray condition.

The 3D morphology of splats was drawn by means of the Pro/ENGINEER ${ }^{\circledR}$ Wildfire 5.0 software (Parametric Technology Corporation, MA, USA). 


\section{Results and Discussion}

\subsection{Wettability Measurement of Glasses and Mild Steel Substrates}

Figure 1 demonstrates the wetability of glass and mild steel substrates. The contact angle of water on glass substrates decreased with time due to the high wettability of glass substrate. The average contact angles were $59.72^{\circ}$ for glass substrates and $117.84^{\circ}$ for mild steel substrates. The measurement interval of mild steel substrate was much smaller than that of glass substrate. Thus, there are more data from mild steel substrate than from glass substrate.

Figure 1. The wetability of glass and mild steel substrates.

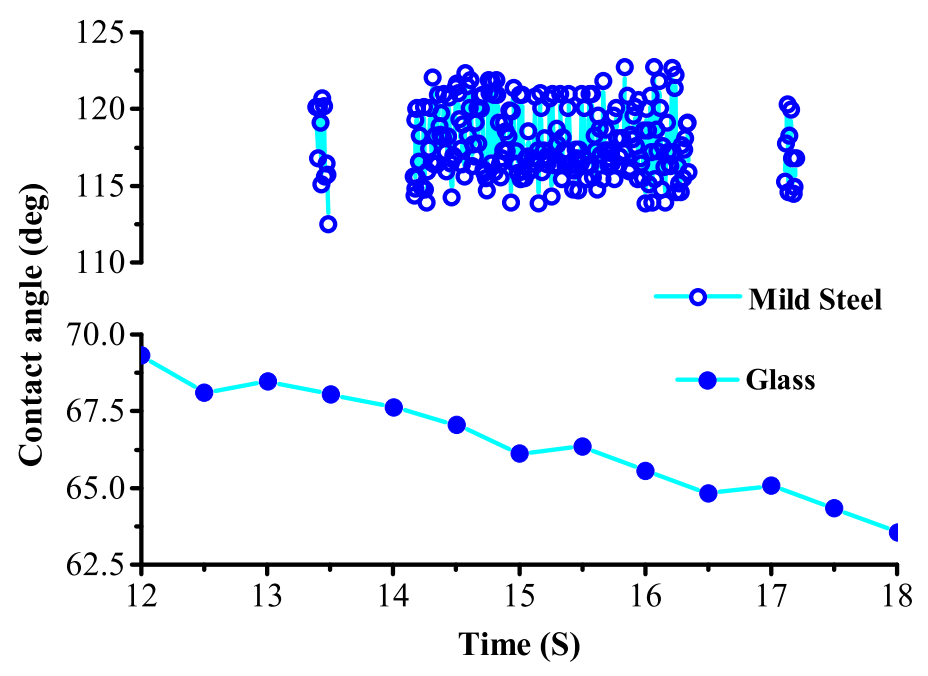

Figure 2 shows the contact angle image on (a) a glass substrate and (b) a mild steel substrate. The picture was taken one minute after the water droplet was placed on the appropriate substrate. The contact angle of glass substrates was smaller than that of mild steel substrates. This result indicated that wettability of glass substrates is higher than that of mild steel substrates since the wettability is defined as the inverse of the contact angle.

Figure 2. The contact angle image of (a) glass substrates and (b) mild steel substrates.

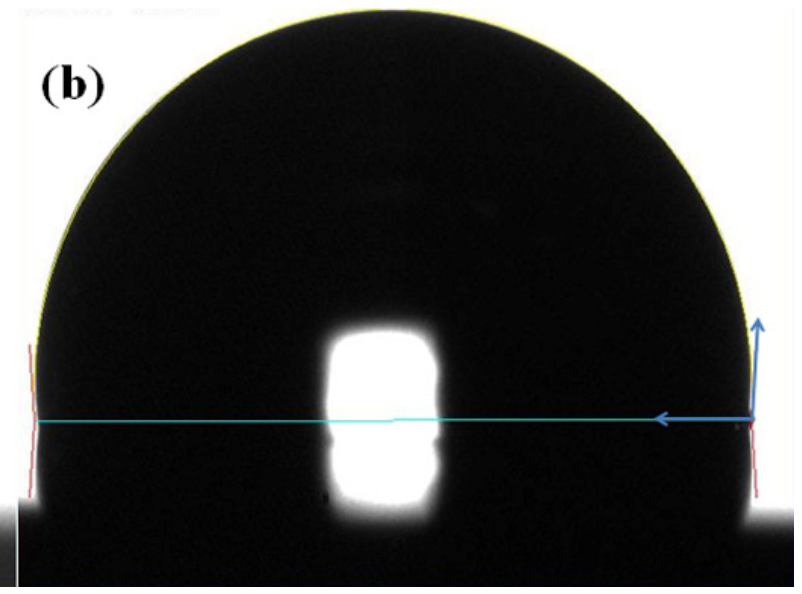




\subsection{Roughness Measurement of Glasses and Mild Steel Substrates}

The average roughness $(\mathrm{Ra})$ of the glass, polished mild steel and gritted mild steel substrates measured by AlphaStep ${ }^{\circledR}$ D-120 Stylus Profiler was $0.013,0.075$ and $2.72 \mu \mathrm{m}$ respectively.

Figures 3 and 4 show the roughness profile of glass and mild steel substrates measured by a VECCO WYKO NT1100 non-contact optical surface profilometer (VECCO, NY, USA). The Ra was $0.01 \mu \mathrm{m}$ and $0.03 \mu \mathrm{m}$ for the glass and polished mild steel substrates, respectively. The roughness of glass substrates was the same as that measured by the AlphaStep ${ }^{\circledR}$ D-120 Stylus Profiler, while the roughness of mild steel substrates was smaller than that measured by the AlphaStep ${ }^{\circledR}$ D-120 Stylus Profiler. The difference between these two results may be attributed to the fact that the mild steel substrates were polished manually. Thus, the roughness of the mild steel substrates could be irregular due to lack of precision and control, while the glass substrates in the form of microscopy glass slides were in the as-received condition from the factory.

Figure 3. The roughness profiles of glass substrates.
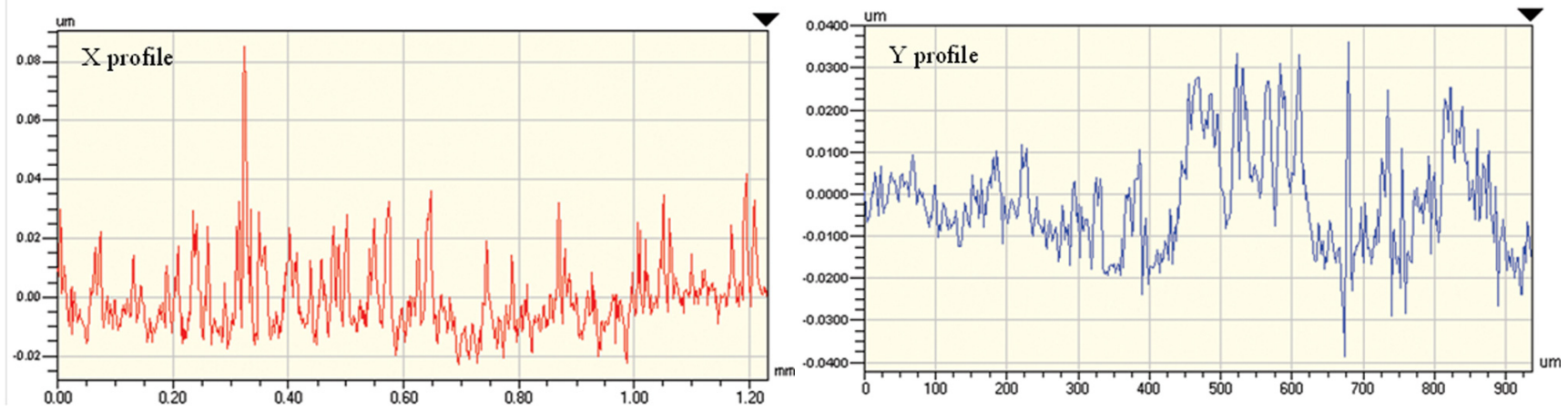

Figure 4. The roughness profiles of polished mild steel substrates.

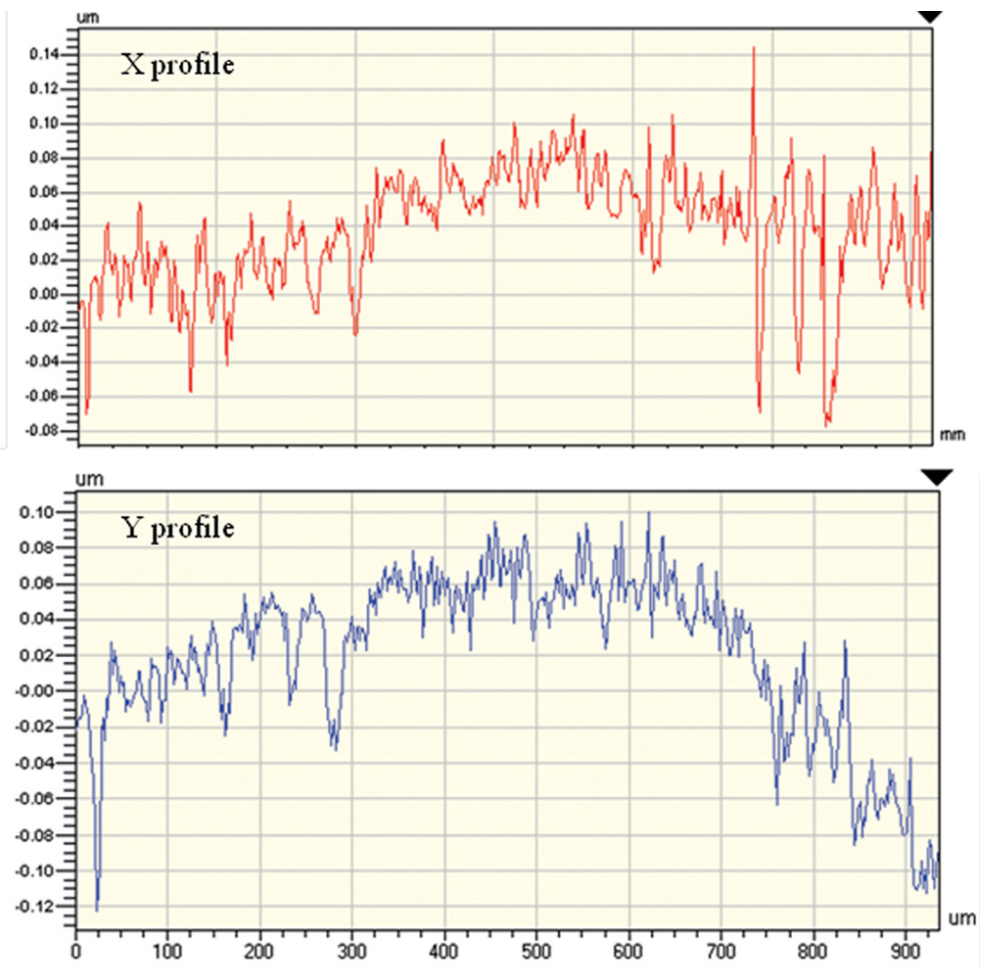




\subsection{Single Splat Characterization by WYKO Surface Profiler and ContourGT}

The disk splats at $20 \mathrm{~cm}$ SOD on the glass substrate were scanned using a WYKO surface profiler that are shown in Figures 5 and 6 respectively. Figure 5a and Figure 6a are three dimensional images of splats; Figure $5 \mathrm{~b}$ and Figure $6 \mathrm{~b}$ are top views of splat, while Figure $5 \mathrm{c}$ and Figure $6 \mathrm{c}$ are splat cross sections. There were bubbles in the center of the splat in Figure 6. The physical measurements of the splashed splat were height $=8.72 \mu \mathrm{m}$, diameter $=250 \mu \mathrm{m}$, area $=49.1 \times 10^{3} \mu \mathrm{m}^{2}$ and volume $=1.95 \times 106 \mu \mathrm{m}^{3}$. The corresponding measurements of the disc splat were height $=39 \mu \mathrm{m}$, diameter $=270 \mu \mathrm{m}$, area $=57.2 \times 10^{3} \mu \mathrm{m}^{2}$ and volume $=1.72 \times 106 \mu \mathrm{m}^{3}$.

Figure 5. Single splat scanned by WYKO surface profiler (a) 3D display; (b) top view and (c) cross section of splat.
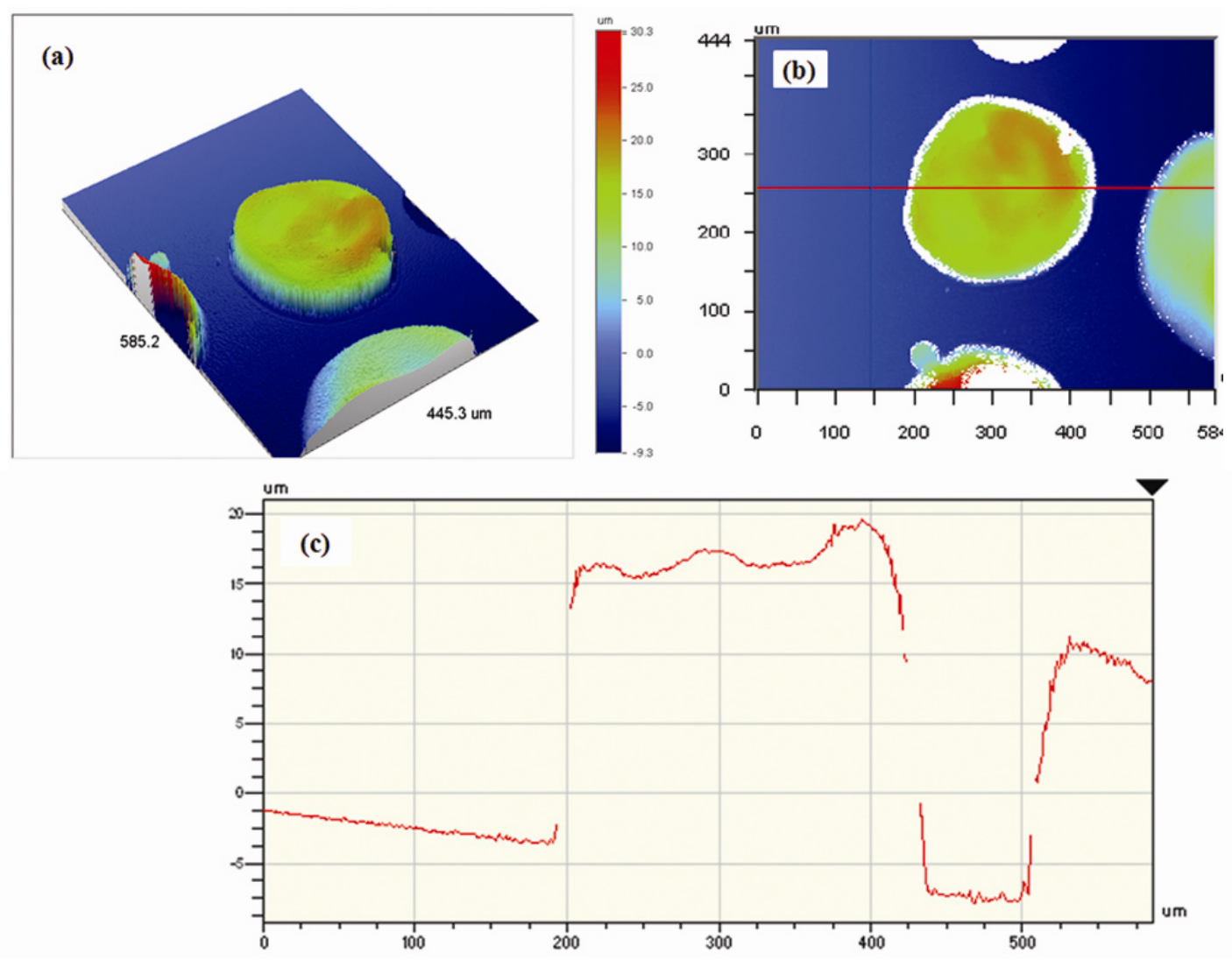

Single splats scanned using a ContourGT surface profiler for (a) disc splat and (b) splashed splat are depicted in Figure 7. The ContourGT surface profiler can characterize a greater area in comparison to the WYKO surface profiler. The patching function of the ContourGT surface profiler allowed several splats to be imaged in one view. The image quality was also better than for the WYKO surface profiler. 
Figure 6. Splat scanned by WYKO surface profiler (a) 3D display; (b) top view and (c) cross section of splat.

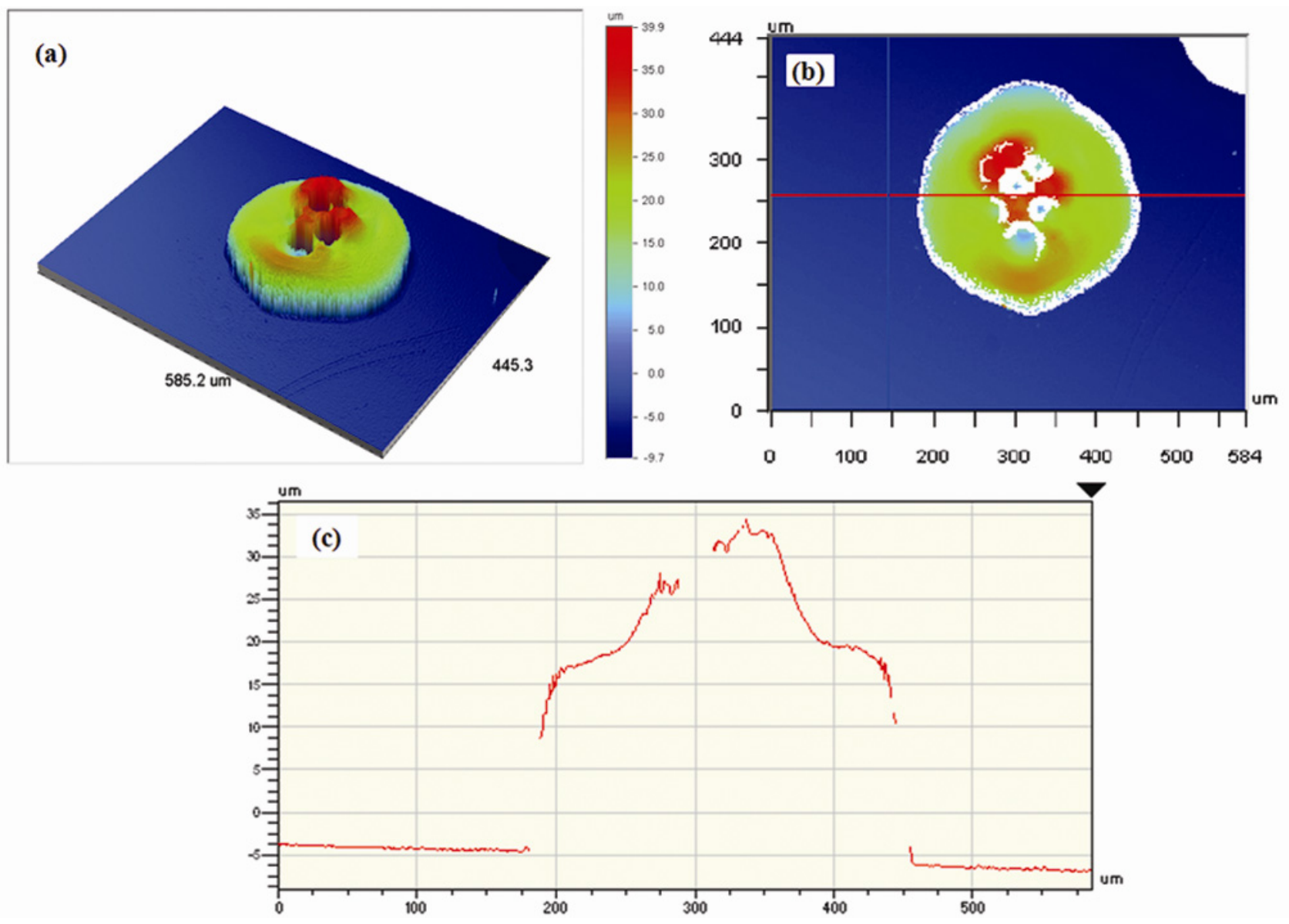

Figure 7. Single splats scanned by ContourGT surface profiler (a) disc splat and (b) splashed splat.

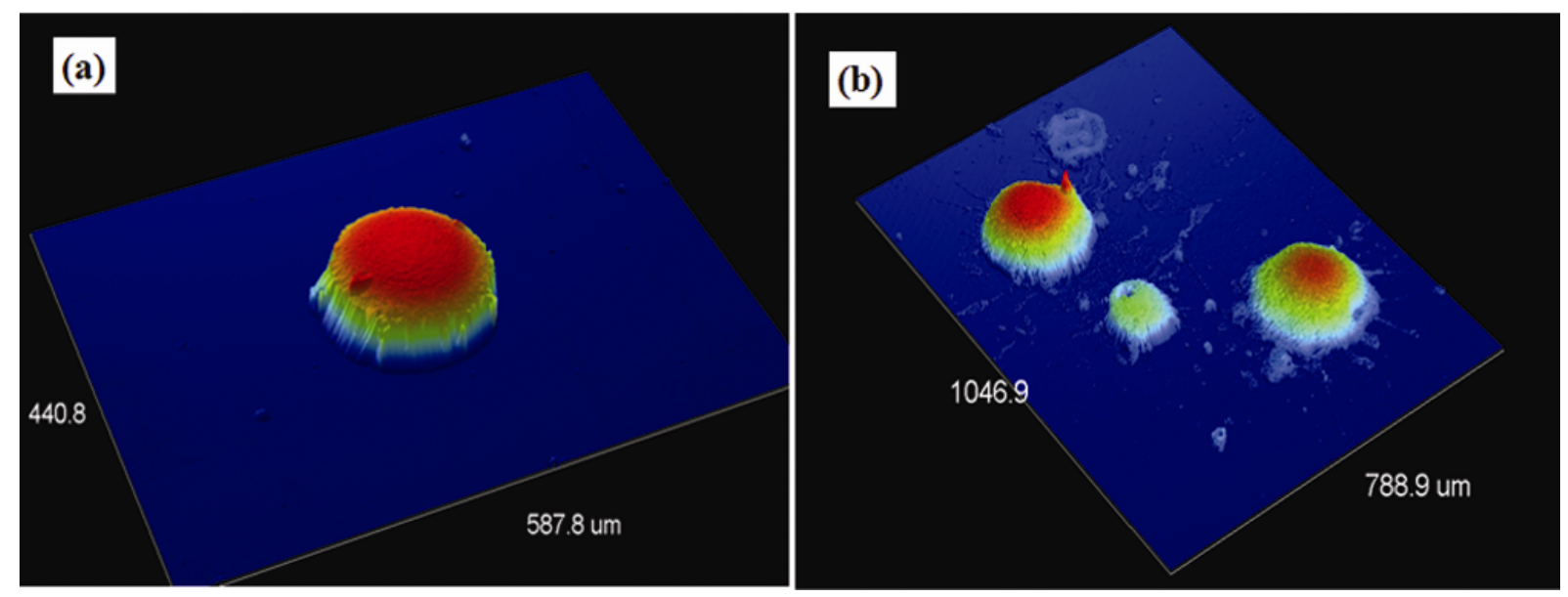




\subsection{Effect of SOD on the Morphology of EMAA Single Splats}

\subsubsection{Morphology of EMAA Single Splats on Cold Substrates}

The effect of SOD on the morphology of EMAA single splat impacts on glass substrates and mild steel substrates are shown in Figures 8 and 9 respectively. A major aim of the following discussion is to establish a physical model between the splat morphologies with respect to the SOD.

On the glass substrates, there were more semi-molten splats or spherical splats at $20 \mathrm{~cm}$ SOD, Figure $8 \mathrm{a}$. When the SOD was increased to $25 \mathrm{~cm}$, more disc splats were observed, Figure $8 \mathrm{~b}$. Increasing SOD to $30 \mathrm{~cm}$ resulted in more fingered splashes and fragmented splashes, Figure 8c. Almost all re-solidified splats or spherical splats were revealed at $35 \mathrm{~cm} \mathrm{SOD}$, Figure $8 \mathrm{~d}$.

For the mild steel substrates, there were more semi-molten splats or spherical splats at $20 \mathrm{~cm} \mathrm{SOD,}$ Figure 9a, which were similar to those features on the glass substrates. More fragmented splashes appeared at $25 \mathrm{~cm}$ SOD, Figure 9b, which was due to (i) the higher thermal conductivity of the mild steel substrates and (ii) a high particle velocity in flight that led to high momentum energy. More disc splats and fingered splashes appeared at $30 \mathrm{~cm}$, Figure 9c and nearly all re-solidified splats or spherical splats can be observed in Figure 9d. More fragmented splashes and spherical splats occurred on mild steel substrates than on glass substrates due to gas release from the mild steel substrate. This result reinforces the importance of substrate preheat treatment to create industrial thermal spray coatings. However, Fukumoto et al. [10] found that splat deposition on gold substrates changed very little between conditions of preheating and no preheating. In this case, the effect of surface chemistry on splat morphology was small, because gold is a noble metal that does not oxidize.

Increasing the SOD resulted in more spherical splats, as shown in Figures 8 and 9. In this case, the low velocity of FS and the rapidly decreased temperature of the jet with spray distance promoted conditions for re-solidification. Spray distances less than $40 \mathrm{~cm}$ are usually preferred to avoid particle re-solidification before impact [26]. However there was a compromise condition since spray distances less than $35 \mathrm{~cm}$ were preferred to avoid particle re-solidification before impact.

A smooth, highly deformed, disc-like splat demonstrated in flight melting since the viscosity of the melting particles was sufficiently low to allow the preferred deformation upon impact. The spherical splat indicated the high viscosity of the melting particles, which were restrained from sufficient deformation upon impact. Such morphological behavior may also result from low impact velocity at high SOD, a higher surface tension coefficient at the melting point, as well as a larger than 90 degree contact angle.

The higher wettability and lower roughness of glass substrates compared with mild steel substrates which were discussed previously contributed to the less fragmentation of splats deposited on glass substrate than that on mild steel substrate.

Single splats are the building blocks of a thermal spray coating. The morphology of single splats is intrinsically related to the properties of thermal spray coatings, thus $25 \mathrm{~cm}$ and $30 \mathrm{~cm}$ SODs for glass substrates and steel substrates are meaningful and practical for the EMAA FS coating industry. 
Figure 8. Stand-off distance (SOD) effect on microstructure of splat and splash splat on glass substrates.

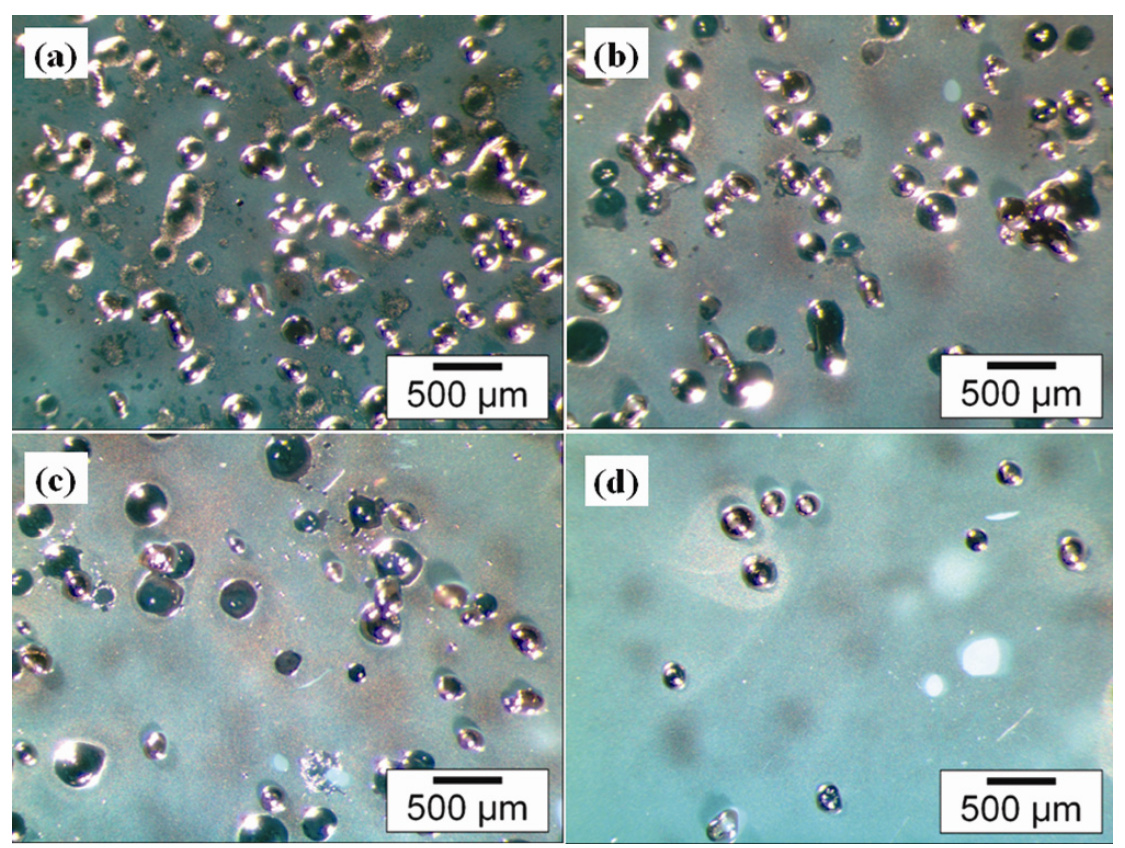

Figure 9. SOD effect on microstructure of splat and splash splat on mild steel substrates.

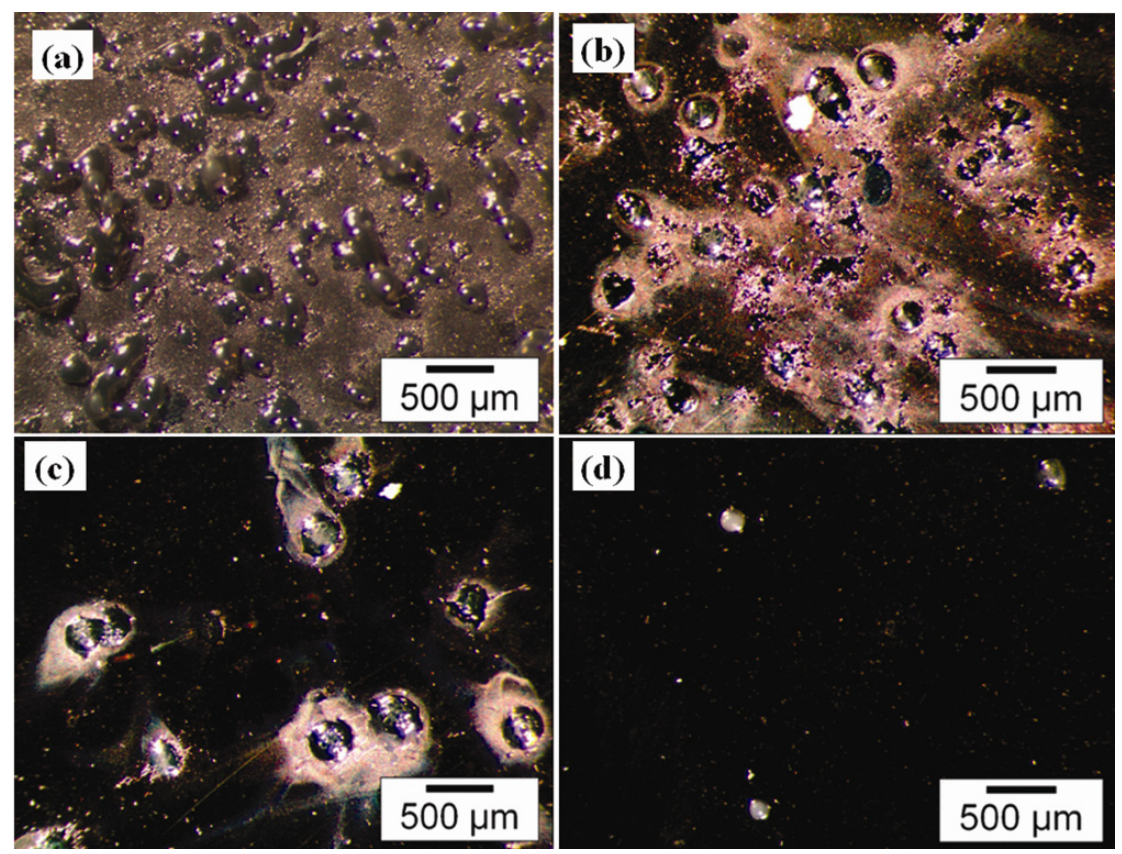

3.4.2. Morphology of EMAA Single Splats Deposit on Heated Substrates

Figure 10 depicts a single splat deposit onto heated glass substrates at (a) $15 \mathrm{~cm}$; (b) $20 \mathrm{~cm}$; (c) $25 \mathrm{~cm}$; and (d) $30 \mathrm{~cm}$ stand-off distances. There were many unmelted splats and some splashing at $15 \mathrm{~cm}$ SOD in Figure 10a. There were more resolidified splats at $25 \mathrm{~cm}$ and $30 \mathrm{~cm}$ SOD; as shown in Figure 10c and Figure 10d. The ideal SOD was determined to be $20 \mathrm{~cm}$ for heated glass substrates. The percentage of splats reduced on increasing the SOD. There were no bubbles in the splats thereby indicating that there were no condensates on unheated glass substrates as shown in Figure 10. 
Figure 10. The single splat deposit on heated glass substrates at (a) $15 \mathrm{~cm}$ stand-off distance; (b) $20 \mathrm{~cm}$ stand-off distance; (c) $25 \mathrm{~cm}$ stand-off distance and (d) $30 \mathrm{~cm}$ stand-off distance.

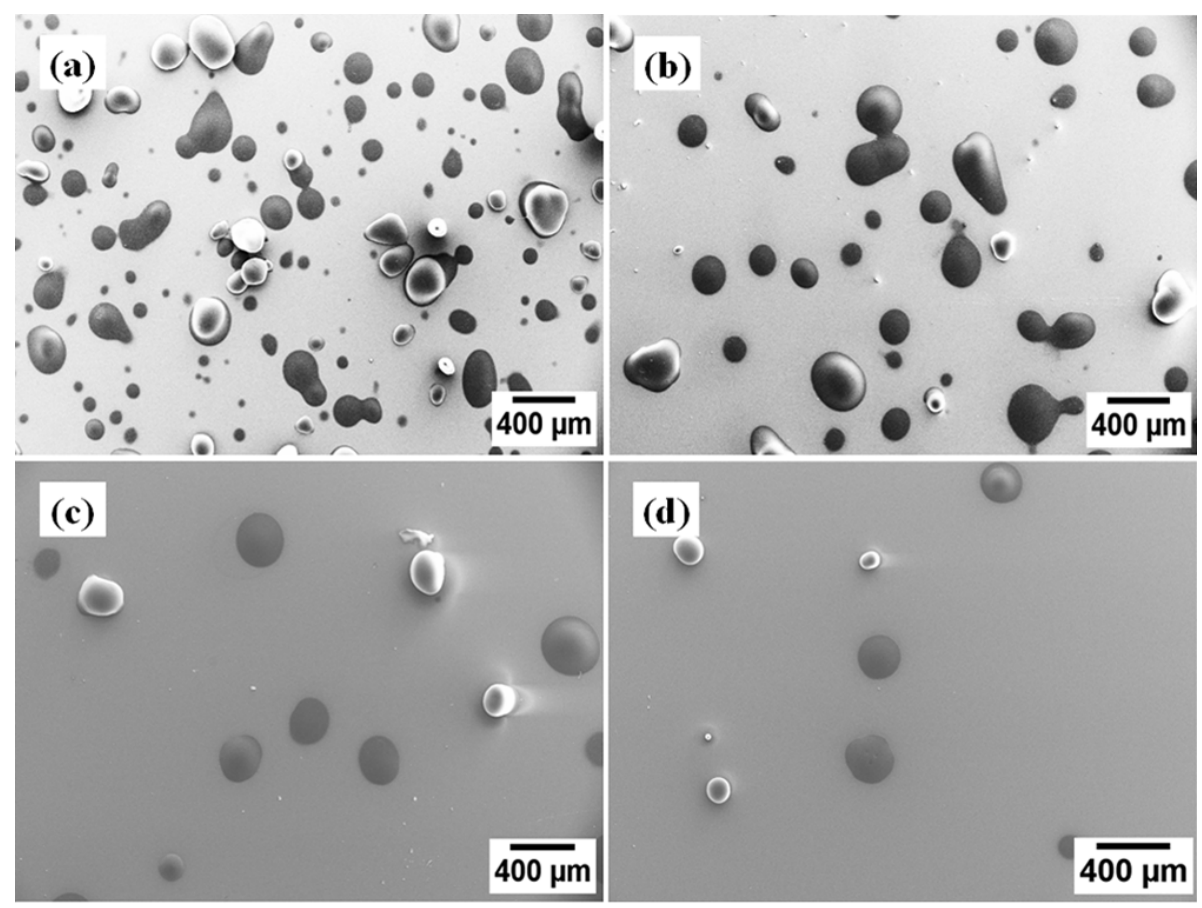

Figure 11. The single splat deposit on heated mild steel substrates at (a) $15 \mathrm{~cm}$ stand-off distance; (b) $20 \mathrm{~cm}$ stand-off distance; (c) $25 \mathrm{~cm}$ stand-off distance and (d) $30 \mathrm{~cm}$ stand-off distance.

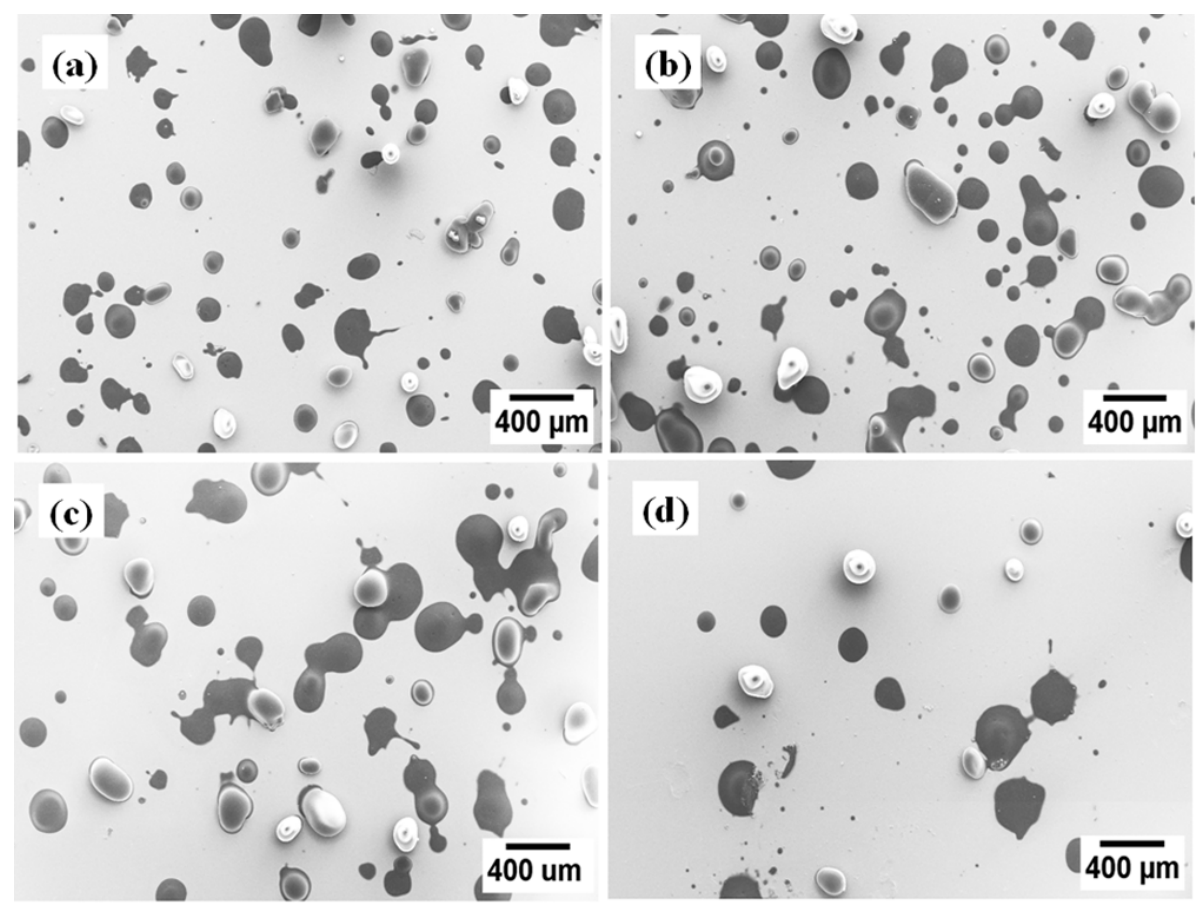

Figure 11 demonstrates a single splat deposit on heated mild steel substrates at (a) $15 \mathrm{~cm}$; (b) $20 \mathrm{~cm}$; (c) $25 \mathrm{~cm}$; and (d) $30 \mathrm{~cm}$ stand-off distances. There were more splashes on heated mild steel substrates than heated glass substrates as shown in Figure 10 due to the difference of thermal conductivity between the mild steel and glass substrates [27]. It is quite likely that more rapid freezing occurred on 
mild steel than on glass substrates due to the higher thermal conductivity of the steel. The thermal conductivity of the mild steel and glass substrates are $36-54 \mathrm{Wm}^{-1} \mathrm{~K}^{-1}$ and $1.09-1.2 \mathrm{Wm}^{-1} \mathrm{~K}^{-1}[28,29]$, respectively, thus the thermal diffusivity of the mild steel was higher than that of the glass substrates. The solidification of the splat bottom impeded the flow of the liquid above and resulted in splashing.

However, the surface of the heated mild steel substrates was much cleaner than the unheated mild steel substrates (Figure 9) due to the effect of the surface chemistry. The gas release from the condensates of the substrate due to input heat from the particle at impact [8-10] caused dramatic splashing. Thus, the surface chemistry of substrates played a more important role than the thermal conductivity of substrates in forming the splat morphologies.

\subsection{The Effect of SOD on Splat Fraction}

Figure 12 demonstrates the effect of SOD on splat fraction. Splat fraction is the ratio of disc splat to splashed splat. The splat fractions on a glass substrate are $72 \%, 63 \%, 97 \%$ and $100 \%$ at $20,25,30$ and $35 \mathrm{~cm}$ SOD, respectively, Figure 12a. The splat fractions on a mild steel substrate are $33 \%, 30 \%, 43 \%$ and $93 \%$ at 20, 25, 30 and $35 \mathrm{~cm} \mathrm{SOD,} \mathrm{respectively,} \mathrm{Figure} \mathrm{12b.} \mathrm{Thus,} \mathrm{the} \mathrm{splat} \mathrm{fraction} \mathrm{on} \mathrm{glass}$ substrates was higher than that on mild steel substrates due to the lower thermal conductivity, higher wettability and lower roughness of the glass.

Figure 12. SOD effect on splat fraction of unheated (a) glass substrates and (b) mild steel substrates.
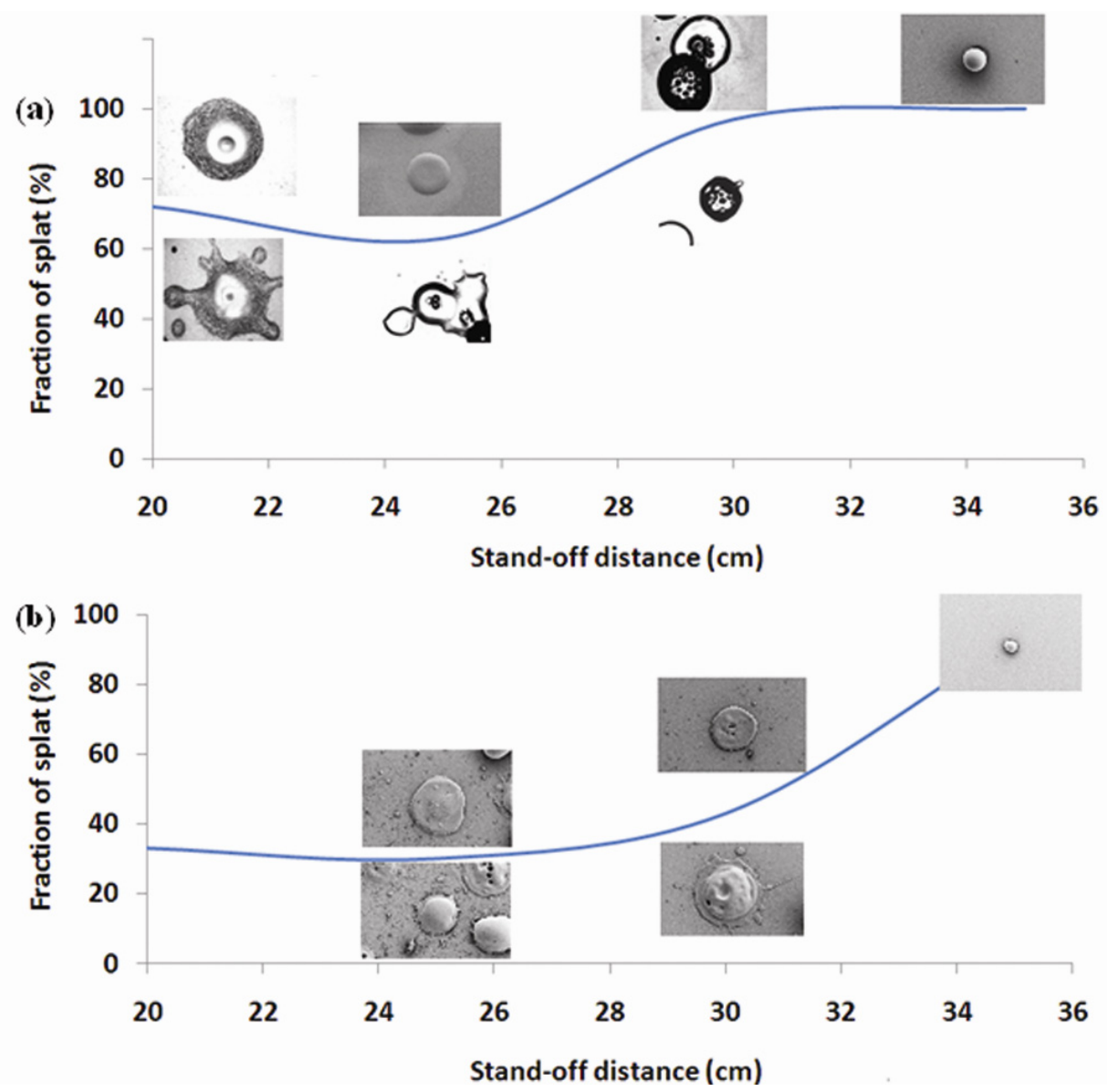


\subsection{Modeling of TV, TS and VS Map}

Figure 13 exhibits the temperature $v s$. velocity (TV) map of EMAA single splats. There are five splat morphology zones according to this TV map. They are (i) resolidified spherical splat zone; (ii) semi-melted spherical splat zone; (iii) disc splat zone; (iv) splashed splat zone; and (v) splash fragment zone. The semi-melted spherical splats and resolidified spherical splats arose when both the particle velocity and temperature were low. The splashed splats and splash fragment were observed when the particle velocity and temperature were high. The disc splat can only appear when the temperature and velocity of particles were in an appropriate range. The highest temperature of EMAA particles was $400{ }^{\circ} \mathrm{C}$ The highest velocity of EMAA particles in propane FS was $35 \mathrm{~m} / \mathrm{s}$ [30,31].

Figure 13. Temperature-velocity (TV) map of EMAA single splats. The lines indicate the approximate fields where the splat morphologies are exhibited.

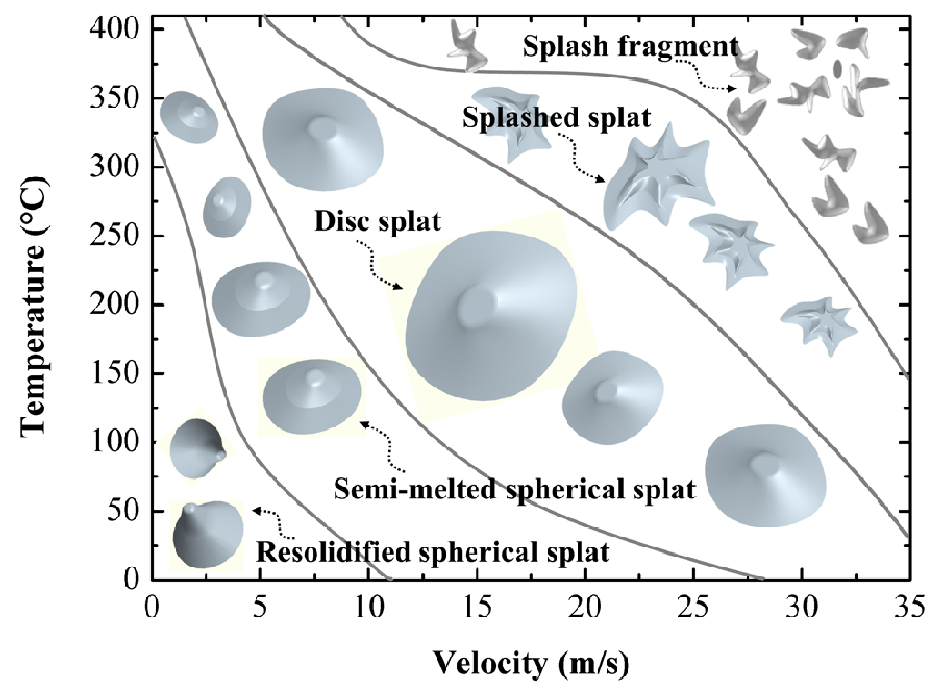

Figure 14 depicts the temperature vs. stand-off distance (TS) map of EMAA single splats. The classification of splat morphology is indicated on the upper lines of the triangle. The semi-melted spherical splats occurred when the particles temperature was low and stand-off distance (SOD) was at $20 \mathrm{~cm}$ to $25 \mathrm{~cm}$. The resolidified spherical splats arose when the temperature was low and the SOD is at $30 \mathrm{~cm}$ to $35 \mathrm{~cm}$. Splashed splats and splash fragments were exhibited when the particle temperatures were high. They occurred between $20 \mathrm{~cm}$ and $30 \mathrm{~cm}$ SOD. The disc splats appeared when the temperature of the particles was in an appropriate range that depended on the velocity. The disc splats normally occurred between $25 \mathrm{~cm}$ and $35 \mathrm{~cm}$ SOD.

Figure 15 presents the velocity vs. stand-off distance (VS) map of EMAA single splats. The classification of splat morphology is depicted on the upper lines of the triangle. Semi-melted spherical splats occurred when the particle velocity was low and stand-off distance (SOD) was from $20 \mathrm{~cm}$ to $25 \mathrm{~cm}$. Resolidified spherical splats were exhibited when the velocity was low and the SOD was from $30 \mathrm{~cm}$ to $35 \mathrm{~cm}$. Splashed splats and splash fragments were produced when the particle velocity was high. They occurred between $25 \mathrm{~cm}$ and $30 \mathrm{~cm}$ SOD. The splash fragments occurred at the highest particle velocity. The disc splats appeared when the velocity of the particles was in an appropriate range. The disc splats occurred between $20 \mathrm{~cm}$ and $35 \mathrm{~cm}$ SOD. 
Figure 14. Temperature-Stand-off (TS) map of EMAA single splats.

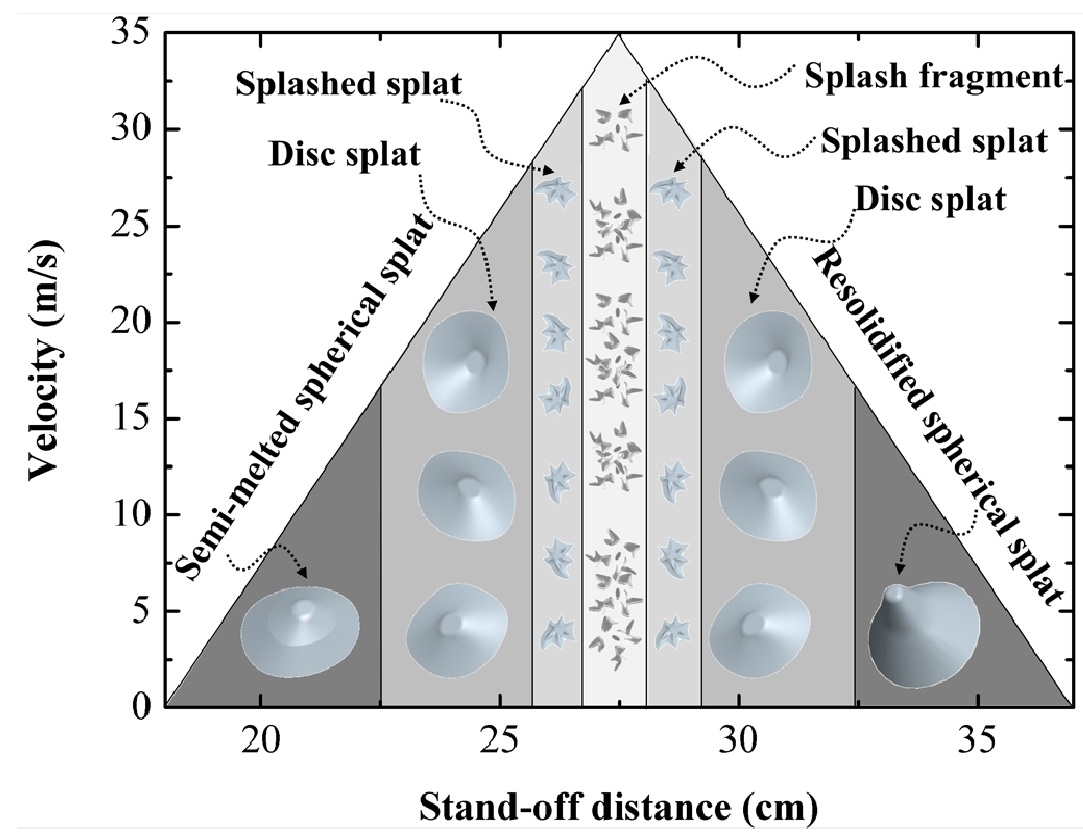

Figure 15. Velocity-Stand-off (VS) map of EMAA single splats.

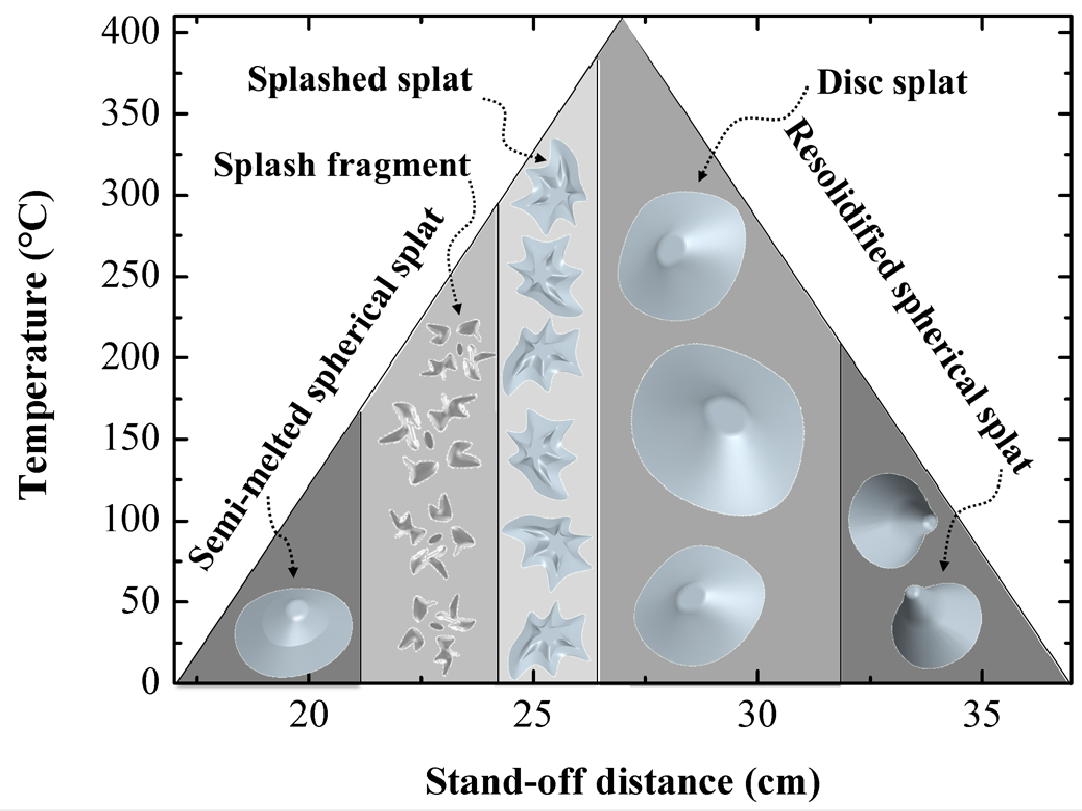

\section{Conclusions}

The lower wettability, higher roughness and higher thermal conductivity of mild steel substrates compared with glass substrates led to more fragmentation of splats deposited on mild steel substrate than that on glass substrate. However, the surface chemistry of substrates played a more important role than wettability, roughness and thermal conductivity in single splat morphology. Substrates heat treatment above transitional temperature significantly reduced the splashed splats.

The prime five morphologies of splats [25]; i.e., (i) semi-molten splats; (ii) re-solidified splats; (iii) disc splats; (iv) splashed splats; (v) fragmented splashes, are modeled position on the temperature 
vs. velocity map. The semi-molten splats and re-solidified splats arose at lower temperatures and velocities, which corresponded to SOD shorter than $25 \mathrm{~cm}$ and SOD longer than $30 \mathrm{~cm}$, respectively. The disc splat was formed at either higher temperatures but lower velocities or moderate temperatures and velocities; which corresponded to SOD's of $25 \mathrm{~cm}$ and $30 \mathrm{~cm}$, respectively. The fingered splash appeared at higher temperatures and velocities that corresponded to SODs of $25 \mathrm{~cm}$ and $30 \mathrm{~cm}$. The fragmented splash occurred at higher velocities under a wide range of temperature conditions.

This study provided practical guidance about the nature of how prime spray variables influenced processing/morphology relationships.

\section{Acknowledgments}

The Thermal Spray Group at Swinburne University of Technology has supported this work. I would also like to thank Elena Ivanova from FLSS for permitting me to access the measuring contact angle instrument. Special thanks to her student Vi Khanh Truong for his help in measuring the contact angle. I am grateful to Nick Birbilis from Monash University for providing access to the WYKO surface profiler. Thanks Scott Wade from IRIS for providing with the training in the ContourGT surface profiler. Wei Xie is the recipient of a Swinburne University Postgraduate Research Award (SUPRA).

\section{Conflict of Interest}

The authors declare no conflict of interest.

\section{References}

1. Fauchais, P.; Fukumoto, M.; Vardelle, A.; Vardelle, M. Knowledge concerning splat formation: An invited review. J. Therm. Spray Technol. 2004, 13, 337-360.

2. Verdian, M.M.; Salehi, M.; Raeissi, K. Effect of feedstock particle size on microstructure of aps coatings prepared from mechanically alloyed nickel-titanium powders. Surf. Eng. 2010, 26, 447-452.

3. Sweet, G.K. Applying Thermoplastic/Thermoset Powder with a Modified Plasma System. In Thermal Spray Coatings: Research, Design and Applications; Berndt, C.C., Bernecki, T.F., Eds.; ASM International: Anaheim, CA, USA, 1993; pp. 381-384.

4. Vardelle, A.; Moreau, C.; Fauchais, P. The dynamics of deposit formation in thermal-spray processes. MRS Bull. 2000, 25, 32-37.

5. Bussmann, M.; Chandra, S.; Mostaghimi, J. Modeling the splash of a droplet impacting a solid surface. Phys. Fluids 2000, 12, 3121-3132.

6. Herman, H.; Sampath, S.; McCune, R. Thermal spray: Current status and future trends. MRS Bull. 2000, 25, 17-25.

7. Jiang, X.; Wan, Y.; Herman, H.; Sampath, S. Role of condensates and adsorbates on substrate surface on fragmentation of impinging molten droplets during thermal spray. Thin Solid Films 2001, 385, 132-141.

8. Tran, A.T.T.; Hyland, M.M.; Qiu, T.; Withy, B.; James, B.J. Effects of surface chemistry on splat formation during plasma spraying. J. Therm. Spray Technol. 2008, 17, 637-645. 
9. Tran, A.T.T.; Hyland, M.M.; Shinoda, K.; Sampath, S. Influence of substrate surface conditions on the deposition and spreading of molten droplets. Thin Solid Films 2011, 519, 2445-2456.

10. Fukumoto, M.; Nagai, H.; Yasui, T. Influence of surface character change of substrate due to heating on flattening behavior of thermal sprayed particles. J. Therm. Spray Technol. 2006, 15, 759-764.

11. Zhao, B.; Yadian, B.L.; Li, Z.J.; Liu, P.; Zhang, Y.F. Improvement on wettability between carbon nanotubes and sn. Surf. Eng. 2009, 25, 31-35.

12. Fukumoto, M.; Nishioka, E.; Matsubara, T. Effect of interface wetting on flattening of freely fallen metal droplet onto flat substrate surface. J. Therm. Spray Technol. 2002, 11, 69-74.

13. Tanaka, Y.; Fukumoto, M. Investigation of dominating factors on flattening behavior of plasma sprayed ceramic particles. Surf. Coat. Technol. 1999, 120-121, 124-130.

14. Christoulis, D.K.; Pantelis, D.I.; Borit, F.; Guipont, V.; Jeandin, M. Effect of Substrate Roughness and Temperature on Splat Formation in Plasma Sprayed Aluminium Bronze. In The 18th International Conference on Surface Modification Technologies, Dijon, France, 2004; pp. 73-83.

15. Tran, A.T.T.; Hyland, M.M. The Role of Substrate Surface Chemistry on Splat Formation during Plasma Spray Deposition by Experiments and Simulations. In International Thermal Spray Conference; Marple, B.R., Hyland, M.M., Lau, Y.-C., Li, C.-J., Lima, R.S., Montavon, G., Eds.; ASM International: Las Vegas, NV, USA, 2009; pp. 462-468.

16. Li, R.; Ashgriz, N.; Chandra, S. Maximum spread of droplet on solid surface: Low reynolds and weber numbers. J. Fluids Eng. Trans. Asme 2010, 132, 061302.1-061302.5.

17. Fukumoto, M.; Huang, Y. Flattening mechanism in thermal sprayed nickel particle impinging on flat substrate surface. J. Therm. Spray Technol. 1999, 8, 427-432.

18. Fauchais, P.; Vardelle, A.; Dussoubs, B. Quo vadis thermal spraying? J. Therm. Spray Technol. 2001, 10, 44-66.

19. Fukumoto, M.; Yamaguchi, T.; Yamada, M.; Yasui, T. Splash Splat to Disk Splat Transition Behavior in Plasma-sprayed Metallic Materials. In International Thermal Spray Conference on Thermal Spray 2007: Global Coating Solutions; Marple, B.R., Hyland, M.M., Lau, Y.-C., Li, C.-J., Lima, R.S., Montavon, G., Eds.; ASM International: Beijing, China, 2007; pp. 905-912.

20. Fauchais, P.; Vardelle, M.; Vardelle, A.; Bianchi, L.; Leger, A.C. Parameters controlling the generation and properties of plasma sprayed zirconia coatings. Plasma Chem. Plasma Process. 1996, 16, S99-S125.

21. Bianchi, L.; Grimaud, A.; Blein, F.; Lucchese, P.; Fauchais, P. Comparison of plasma-sprayed alumina coatings by rf and dc plasma spraying. J. Therm. Spray Technol. 1995, 4, 59-66.

22. Brogan, J.A. Processing and property relationships of thermally sprayed polymer systems. Ph.D. Thesis, State University of New York, Stony Brook, NY, USA, 1996.

23. Leger, A.C.; Vardelle, M.; Vardelle, A.; Dussoubs, B.; Fauchais, P. Splat Formation: Ceramic Carticles on Ceramic Substrates. In Advances in Thermal Spray Science \& Technology; Berndt, C.C., Sampath, S., Eds.; ASM International: Houston, TX, USA, 1995; pp. 169-174.

24. Sampath, S.; Jiang, X.Y.; Matejicek, J.; Leger, A.C.; Vardelle, A. Substrate temperature effects on splat formation, microstructure development and properties of plasma sprayed coatings part i: Case study for partially stabilized zirconia. Mater. Sci. Eng. A 1999, 272, 181-188. 
25. Xie, W.; Wang, J.; Berndt, C.C. Spreading behavior and morphology of ethylene methacrylic acid (emaa) deposits via the flame spray process. Coatings 2012, 2, 76-93.

26. Petrovicova, E.; Schadler, L.S. Thermal spraying of polymers. Int. Mater. Rev. 2002, 47, 169-190.

27. Jiang, X.; Matejicek, J.; Sampath, S. Substrate temperature effects on the splat formation, microstructure development and properties of plasma sprayed coatings part ii: Case study for molybdenum. Mater. Sci. Eng. A 1999, 272, 189-198.

28. Lide, D.R. Crc Handbook of Chemistry and Physics; CRC Press: London, UK, 1995; p. 182.

29. Bejan, A.; Kraus, A.D. Heat Transfer Handbook; John Wiley \& Sons: Hoboken, NJ, USA, 2003.

30. Davis, J.R. Handbook of Thermal Spray Technology; ASM International: Materials Park, OH, USA, 2004; p. 338.

31. Brogan, J.A.; Berndt, C.C. The coalescence of combustion-sprayed ethylene-methacrylic acid copolymer. J. Mater. Sci. 1997, 32, 2099-2106.

(C) 2013 by the authors; licensee MDPI, Basel, Switzerland. This article is an open access article distributed under the terms and conditions of the Creative Commons Attribution license (http://creativecommons.org/licenses/by/3.0/). 